\title{
ATIVIDADES EDUCATIVAS NÃO FORMAIS REALIZADAS NO MUSEU DE ARTE CONTEMPORÂNEA - MARCO DE MATO GROSSO DO SUL
}

\section{NON-FORMAL EDUCATIONAL ACTIVITIES PERFORMED AT THE MUSEUM OF CONTEMPORARY ART - MARCO DE MATO GROSSO DO SUL}

\author{
Catia Regina Madella ${ }^{1}$ \\ Maria Augusta de Castilho ${ }^{2}$ \\ Maria Christina de Lima Félix Santos ${ }^{3}$
}

Doi: 10.36066/compcs.v1i23.8034

\begin{abstract}
Resumo: O presente artigo pretende ressaltar a importância do museu na construção do conhecimento formal e não formal. Destacar o interesse crescente do cidadão comum pelo espaço museal, na condição de guardião da memória coletiva. E apresentar o exemplo prático do Museu de Arte Contemporânea - MARCO-MS, enquanto casa de memória e espaço de preservação da história da arte sul-mato-grossense, bem como a sua importância no fazer educativo não formal.
\end{abstract}

Palavras-chaves: Museu, conhecimento, ações educativas não formais, Arquitetura, arte contemporânea.

Abstract: This article intends to emphasize the importance of the museum in the construction of formal and non - formal knowledge. To highlight the growing interest of the ordinary citizen in the museum space, as guardian of collective memory. And to present the practical example of the Museum of Contemporary Art - MARCO-MS, as a house of memory and space of preservation of the history of South-Mato Grosso art, as well as its importance in non-formal education.

Keywords: Museum, knowledge, non-formal educational actions, Architecture, contemporary art.

\section{Introdução}

A palavra museu teve origem na Grécia Antiga, derivada de Mouseion, termo que denominava o templo dedicado às novas musas, divindades menores do panteão grego e que eram ligadas a diferentes ramos da arte e da ciência, sendo filhas de Zeus com Mnemosine, deusa da memória (IPHAN, 2006). Até o século XVII, os museus eram basicamente locais onde se preservavam documentações importantes e nesses locais ficavam dispostos para estudos e análises. A partir do século XVII, passaram a se constituir os museus modernos, criados com doações particulares. O primeiro museu conhecido é o Ashmolean Museum, no ano de 1683, em Oxford, Reino Unido, que surgiu com doações de Elias Ashmole, da coleção de John Tradescant. O segundo museu público é o Museu Britânico, de 1759 e o primeiro

\footnotetext{
${ }^{1}$ Mestrado/doutorado em Desenvolvimento Local- Universidade Católica Dom Bosco - UCDB. Av. Tamandaré 6000. Tel:. 55 (67) 33123800. arquiteturaecia@terra.com.br

${ }^{2}$ Docente mestrado/doutorado em Desenvolvimento Local - UCDB

${ }^{3}$ Doutorado em Desenvolvimento Local - UCDB

Compocs, v1, n 23 - jul -dez 2020
} 
público na França é o Louvre de 1793. No Brasil, o primeiro museu fundado foi em 1862, do Instituto Arqueológico Histórico e Geográfico Pernambucano; todos os outros museus brasileiros datam do século XX, e o mais importante pela qualidade de acervo é o Museu de Arte de São Paulo Assis Chateaubriand - MASP, de 1947.

A formação dos museus é também influenciada pela relação da humanidade com a memória e a história.

O museu retém o saber que os olhos deixam de observar no cotidiano, faz com que se possa lembrar o que está adormecido nas mentes e ainda nos devolve o cotidiano de povos que não existem mais, mas foram os construtores do presente e por isso não devem ser esquecidos (CASTILHO; FERREIRA, 2012, p. 31-32).

Os museus são especialistas na recordação da memória, que estabelece um papel importante na construção do imaginário e da identidade de uma sociedade (HELLWIG, 2014).

De acordo com o Conselho Internacional de Museus:

O museu é uma instituição permanente sem fins lucrativos, ao serviço da sociedade e do seu desenvolvimento, aberta ao público e que promove pesquisas relativas aos testemunhos materiais do homem e do seu ambiente, adquire-os, conserva-os, comunica-os e expõe-nos para estudo, educação e prazer (DESVALLÉES; MAIRESSE, 2013, p. 64).

Para Noronha o Museu de Arte Contemporânea firma-se no pressuposto do seu desenvolvimento:

[...] durante o século XX, concomitante ao desenvolvimento das investigações museológicas e ao estabelecimento da Museologia enquanto disciplina. Algumas consequências: a possibilidade do Museu de Arte Contemporânea ser apresentado e apresentar-se como uma instituição que se estabelece em um contexto cultural, político e econômico e que está sujeita a redefinições conforme os interesses e mudanças desse próprio contexto. Se os primeiros cento e cinquenta anos do Museu de Arte Contemporânea foram marcados por um processo de institucionalização, ou seja, de incorporação e acumulação de um conjunto de conquistas históricas, normas e valores que tendiam a gerar as condições de sua própria reprodução (Bourdieu, 1989: 100), os últimos cinquenta anos foram marcados por um processo de reflexividade, ou seja, de pôr em causa de modo radical suas próprias práticas e seus próprios instrumentos de consolidação, abrindo-se a ações que tensionam o lugar privilegiado 
que seu discurso ocupa no contexto político e sociocultural em que se insere (NORONHA, 2010, s/p).

O IBRAM estabelece como princípios fundamentais dos museus, na Lei $\mathrm{n}^{\circ} 11.904$, de 14 de janeiro de 2009, Estatuto dos Museus, em seu art. $2^{\circ}$, que os museus devem buscar:I- a valorização da dignidade humana;II- a promoção da cidadania; III- o cumprimento da função social;IV- a valorização e preservação do patrimônio cultural e ambiental; $\mathrm{V}$ - a universalidade do acesso, o respeito e a valorização à diversidade cultural;VI- o intercâmbio institucional.

Os museus adquirem, por intermédio das práticas educativas não formais, força e visibilidade, passando a ser visto como espaço para a disseminação do conhecimento e formação. Também estabelece a legislação que os museus deverão promover ações educativas, fundamentadas no respeito à diversidade cultural e na participação comunitária, contribuindo para ampliar o acesso da sociedade às manifestações culturais e ao patrimônio material e imaterial da Nação.

Dessa forma, o triple, da identidade deum museu, que consiste em: ter sua coleção organizada, da mesma ser de acesso ao público e de proporcionar ações educativas. Garante-se formalmente, e hoje não há a política do gabinete de curiosidades, ou seja, exclusivamente de visitações e verificação de coleções.

\section{Museu e memória}

Muito além de casas de memória, os museus constituem em casas da vida de um país, marcam da formação de seu território. São espaços construtos que assumem cada vez mais sua função junto ao povo, e conforme preconiza o IBRAM, são casas de conhecimento, vivência e transformação.

Le Goff (1996) assevera que a memória é a propriedade de conservar certas informações, propriedade que se refere a um conjunto de funções psíquicas que permitem ao indivíduo atualizar impressões ou informações passadas, ou reinterpretadas como passadas. Assim a memória se alicerça aos fundamentos da História, confundindo-se muitas e tantas vezes com o documento, com o monumento e com a oralidade.

De acordo com Todorov (2002, p. 141), “a memória é a vida do passado no presente”, ou seja, é a memória que nos permite conhecer as permanências e compreender as transformações. 
Todas essas lembranças, histórias e memórias são hoje relatadas aos mais novos por meio da história oral, e quando falamos de história oral vemos que esse é um processo de recordação construtivo e que depende da situação presente: "na maior parte das vezes, lembrar não é reviver, mas refazer, reconstruir e repensar as imagens de hoje, as experiências do passado" (BOSI, 1994, p. 55).

Aliando a história oral à formação da memória, Von Simson relata que a história oral possibilita que indivíduos pertencentes a categorias geralmente excluídas da história oficial possam ser ouvidos, deixando registradas para análise futura sua própria visão de mundo e aquela do grupo social ao qual pertencem. Portanto, possibilita que se reavivando a memória daqueles que fizeram a história, e por meio desse mecanismo, a preservação está garantida (VON SIMSON, 2000).

O resgate da memória significa o meio pelo qual se produz a continuidade temporal. Muitos estudiosos declaram que a memória pode ter duas grandes classificações: a memória individual e a coletiva.

Para Halbwachs (1990) a memória individual é um ponto de vista sobre a memória coletiva, mudando o foco conforme o lado ocupado. O autor apresenta a seguinte reflexão: “[...] a sucessão de lembranças, mesmo daquelas que são mais pessoais, explica-se sempre pelas mudanças que se produzem em nossas relações com os diversos meios coletivos, isto é, pelas transformações desses meios, cada um tomado à parte e em conjunto" (HALBWACHS, 1990, p. 82).

No aporte de Kessel (2010) a memória coletiva serve de referência para a construção do sentimento de pertença local, subsidiando a estruturação da memória individual nos campos histórico e simbólico. A autora reforça a relação da memória com o ambiente, o lugar, pois para moldar fatos pré-ocorridos a referência do lugar auxilia na estruturação da memória, assim como a oralidade é base para a construção da memória individual.

Paul Thompson (1992, p. 197) afirma que "toda fonte histórica derivada da percepção humana é subjetiva, mas apenas a fonte oral permite-nos desafiar essa subjetividade”.

Quanto à relação da memória com a narratividade, é imprescindível saber que o fato de registrar aviva a memória e grava para a posteridade dados e feitos importantes.

O narrador está presente ao lado do ouvinte. Suas mãos experimentadas no trabalho fazem gestos que sustentam a história, que dão asas aos fatos principiados pela sua voz. Tira segredos e lições que estavam dentro das coisas, faz uma sopa deliciosa das pedras do chão, como no conto da Carochinha. A arte de narrar é uma relação 
alma, olho e mão: assim transforma sua matéria, a vida humana (BOSI, 1994, p. 90).

As narrativas contribuem para a composição de imagens da história passada àqueles que não viveram os fatos. "O registro das histórias permite uma compreensão do modo de ser do indivíduo e do contexto social, de sua profissão, não como realmente existiu, mas como estes próprios sujeitos reconstroem suas experiências passadas" (FONSECA, 1993, p. 34).

“A memória poderá ser conservação ou elaboração do passado [...]”. (BOSI, 1994, p. 68). Refletindo a respeito da teoria de Bosi, é possível crer que, por meio da memória, não importando seu caráter individual ou coletivo, é possível a uma comunidade proteger sua história, conhecendo o passado para constantemente reconstruir o presente com base nas experiências pregressas.

\section{Arquitetura de museus -o museu contemporâneo}

Kiefer expõe que desde pelo menos a Roma Antiga, os arquitetos dedicam-se a dar receitas escritas de como fazer a boa arquitetura. A simples leitura dos principais tratados de cada época ou o significado de sua ausência dá uma boa medida da evolução ou transformação por que passou a arquitetura (KIEFER, 2000). O primeiro desses tratados de que se tem notícia, não se dedicou aos museus porque esses simplesmente não existiam (VITRUVIO, 1995). Os museus ganham um verbete com alguns desenhos e o autor destaca que os museus deveriam ser erigidos dentro do mesmo espírito das bibliotecas, ou seja, um edifício que guarda um tesouro público e que é, ao mesmo tempo, um templo consagrado aos estudos (DURAND, 2014).

É importante ressaltar essa associação com as bibliotecas, porque ela dá a justa medida do caráter educativo que predominava nos primeiros museus (KIEFER, 2002). Os museus vieram substituir as catedrais na função de bíblia pauperum, dentro da ideia jacobina de que a visão do Belo conduziria à ideia do Bem (BESSET, 1993). Mas essa função educativa também era muito mais literal, pois os museus eram verdadeiras escolas onde os aprendizes montavam seus ateliês e passavam o dia todo em frente das telas que deveriam copiar. É o que se vê no projeto de Durand, exemplificando o verbete museus, em Précisdesleçons d'architecture, em que, ao longo das galerias de exposição, distribui-se uma infinidade de cabinets des artistes. 
Essas duas maneiras de ver os museus como templo guardião de tesouros sagrados ou como escola estão presentes, de alguma forma, em todos os projetos de seus novos edifícios. Uma vê a arte como fruto de uma essência atemporal e a outra como de feitos históricos perfeitamente determinados. A forma de panteon, circular e monumental vai responder aos anseios da primeira visão; as galerias, sequenciando a visita, vão responder à segunda (KIEFER, 2002).

Fazendo uma analogia e trazendo a arquitetura de museus para os dias atuais, como espaços contenedores da arte contemporânea, pode-se afirmar que, assim como a arte é atemporal, os museus deveriam suportar todas as formas de manifestações artísticas. A arte contemporânea tem diversos significados, questionamentos e vários autores apresentam definições que podem indicar o caminho para os projetos arquitetônicos de museus contemporâneos.

Arte contemporânea é toda expressão artística que revela, em traços ou por inteiro, a atualidade da vida social - local ou mundial. Assim, cada momento da sociedade, cada mudança visível de um grupo social, pode ser representado e percebido nos seus vários suportes. Historicamente esse tempo social é geralmente longo, suficiente para gerar um movimento artístico [...] (VERUNCHK, 2009, s/p).

Ainda de acordo com Tiburi, a arte contemporânea:

É um conceito que, a meu ver, vale mais como produto da 'arte conceitual' do que como recorte histórico que signifique algo. $\mathrm{Na}$ verdade, é uma definição anacrônica, tanto quanto a arte conceitual, que nasceu da crise dos críticos [...]. Também a palavra arte se tornou anacrônica. Ninguém entende de arte, nem de arte conceitual. Nem de conceitos. Não temos, é claro, aparato conceitual que dê conta dos fenômenos. Em outras palavras: 'arte contemporânea' é uma definição que usamos vagamente para sinalizar que nas produções atuais vemos algo de arte. Mas não sabemos o que é arte e ficamos a insistir em arte contemporânea por falta de domínio conceitual. Círculo vicioso, sim. [...] Mais importante é avaliar que estamos no tempo da performance, do design e do espetáculo. Performance é o que há de mais parecido com o que chamávamos de arte, design com o que envolvia conceitos, espetáculo com o que chamávamos cultura de massa. Enquanto as categorias permanecerem em tensão, nossa cultura tem futuro [...] (VERUNCHK, 2009, s/p).

Por definição, contemporâneo é o que ou aquele que é do mesmo tempo, que existiu ou viveu na mesma época, ou que é do tempo atual. A arte contemporânea é sempre um 
assunto do momento e recorrentemente debatido em todos os simpósios e bienais sobre arte. Provavelmente, é essa discussão que a alimenta em todo o mundo (SANTOS, 2016).

Santos descreve que a principal característica da arte contemporânea é o abandono dos suportes tradicionais. Com o abandono da tela, do bronze e do mármore surgiram outros suportes e, depois, simplesmente foram abolidos por alguns ditos contemporâneos. A arte conceitual dos anos de 1960, que talvez tenha consolidado o processo, passou a trabalhar mais com a cabeça do que com as mãos.

Sendo assim, tamanho, forma e características têm exigido a transformação do espaço de exibição. Artbrut, pop art, landart, minimalismo, videoarte, happenings, performances, instalações e tantos outros meios artísticos, interativos ou efêmeros, começaram a ditar suas próprias leis e guiar sua exposição em um museu (KIEFER, 2000).

Mudou a arte, mudou a arquitetura. Os novos museus devem estar inseridos na cidade, e segundo Searing devem ser o verdadeiro caminho de ligação com a cidade, reavaliando a relação da edificação com o urbano (SEARING, 1982).

Algumas características arquitetônicas para estes Novos Museus são ressaltadas por Montaner (1990) e, em destaque, estão os projetos das grandes caixas hightech onde todas as funções são distribuídas em seu interior homogêneo, a articulação em uma unidade muito clara, de elementos independentes que abrigam diferentes funções, é a segunda possibilidade de projeto, a reciclagem de edifícios ou de conjuntos de edifícios históricos das cidades pode ser outra linha de concepção arquitetônica e museus construídos em zonas rurais que apresentam a possibilidade de dispersão.

Segundo Montaner (1990), pode-se considerar um quinto tipo que é a atualização, através de reformas modernizadoras de museus existentes, a exemplo do Louvre em Paris e do Metropolitande Nova Iorque.

\begin{abstract}
A arquitetura do museu contemporâneo se reveste de dupla relevância tanto para o sistema da arte quanto para a reflexão arquitetônica de vanguarda e passa inevitavelmente pela ponderação dos binômios forma-função, espaço-evento e público-privado. Como por aí também cruzará a permanência do museu como lugar historicamente privilegiado para o contato entre arte e público, e as possíveis reproposições dos paradigmas expositivos e arquitetônicos envolvidos (SPERLING, 2012, s/p).
\end{abstract}

Portanto, pode-se concluir que a solução para este enredamento resultou na criação de espaços serventes, cada vez mais complexos e que adquiriram uma nova importância cultural, 
social, educacional, como locais de expressão de todas as artes, sem barreiras ou interferências espaciais, integradores.

\section{O museu de arte contemporânea do MS- marco}

O Museu de Arte Contemporânea - MARCO de Mato Grosso do Sul, ao longo de seus anos de história, é palco de importantes exposições. Constitui-se em casa de memória e história, salvaguarda da memória da arte de Mato Grosso do Sul e tem revelado artistas para o cenário nacional e internacional. Centro de referência para as artes plásticas no estado de MS, criado em 17 de dezembro de 1991, teve a primeira sede instalada em um prédio na esquina da Avenida Calógeras com a Rua Cândido Mariano, na região central de Campo Grande MS.

A sede definitiva de imponente arquitetura, em concreto, foi projetada pelo arquiteto e urbanista Emmanuel de Oliveira, de 1993 - 2002, com recursos da Lei de Incentivo à Cultura. Desde então, as artes sul-mato-grossenses tomaram um novo impulso, dada a possibilidade de um diálogo maior com as artes de outras regiões e a oportunidade de divulgação da produção artística local, respeitando e valorizando a diversidade de linguagens e temas aqui abordados, contribuindo significativamente para a consolidação da arte e da cultura desse estado.

$\mathrm{O}$ acervo do MARCO/MS tem origem na Pinacoteca Estadual, com os prêmios aquisitivos dos salões de arte, realizados a partir de 1979 e, mais tarde, através de doações espontâneas de artistas, colecionadores e instituições culturais. Atualmente, compõe-se de aproximadamente 1600 obras, em diversas modalidades artísticas, incluindo um conjunto significativo que registra o percurso das artes plásticas em Mato Grosso do Sul.

A inauguração da atual sede do Marco deu novo impulso ao movimento artístico do Estado, ampliando o calendário anual e possibilitando um número maior de exposições. $\mathrm{O}$ critério de escolha dos trabalhos a serem expostos no Museu é feito por intermédio de editais lançados anualmente entre outubro e novembro. O trabalho de seleção é feito por artistas, professores e críticos no mês de fevereiro. As exposições selecionadas compõem o calendário anual do museu, com trocas realizadas a cada dois meses.

O acervo contempla uma coleção com mais de 1500 obras nas mais diversas linguagens: pinturas, esculturas, objetos, fotografias, desenhos, gravuras e uma coleção especial com todo o acervo (diários, fotografias, pinturas e documentos) de Lídia Baís, uma das pioneiras das artes plásticas modernas do estado e Ignês Corrêa da Costa, aluna de Portinari que colaborou em obras como os murais azulejados e os painéis do auditório do 
Palácio Gustavo Capanema, no Rio, além da Igreja da Pampulha em Belo Horizonte. Entre as obras de artistas sul-americanos no acervo do Marco estão os argentinos Fernando Suárez (pintura) e Maria Perez Sola (gravura) e os fotógrafos paraguaios Luiz Vera e Juan Britos. Da região Centro Oeste possui obras de Divino Sobral, Darlan Rosa, Gervane de Paula, Omar Franco, Glenio Lima, Elder Rocha, Marcelo Solá, Maria Guilhermina e Marina Boaventura.

O MARCO conta ainda com uma coleção de 14 obras de artistas brasileiros doada por Pietro Maria Bardi, 30 xilogravuras de Oswald Goeldi, 25 gravuras do Projeto Bozano Arte e Natureza, com nomes como Beatriz Milhazes, Daniel Senise, Flávio Shiró, Carlos Vergara, Siron Franco e Tomie Ohtake.

Foi contemplado na $2^{\mathrm{a}}$ edição do Prêmio Marcantonio Vilaça para "Aquisição de Acervos", com obras de três importantes artistas de relevância para a arte local- Wega Nery, Ignês Corrêa da Costa e Jorapimo.

Recebeu a exposição “Quilombolas - Tradições e Cultura da Resistência”, em 2008, consistindo em um registro fotográfico, inédito, realizado pelo fotógrafo documentarista André Cypriano em negativo convencional preto-e-branco tratado digitalmente, resultado da pesquisa de campo em 11 comunidades negras remanescentes dos quilombos no Brasil. A exposição itinerante contou com o patrocínio da Petrobras e de recursos da Lei Rouanet de Incentivo à Cultura. No mesmo ano, a Ginga Cia. de Dança, sob a coordenação da bailarina Renata Leoni, escolheu uma das salas do Marco para apresentação do espetáculo, Estudos de superfície, contemplado pelo prêmio Klauss Vianna 2011 da Fundação Nacional de Artes/Funarte marcando os 25 anos da companhia. Um ano depois, o acervo do museu foi contemplado com 64 gravuras em cliché-verre de Alex Cerveny, premiado pela $5^{\text {a }}$ Edição do Prêmio Marcantonio Vilaça/Funarte. Em 2014, a mostra Ka-ta-pumba, instalação do artista plástico paulistano Laerte Ramos, premiada na $7^{\mathrm{a}}$ edição do edital Marcantônio Vilaça (Funarte/MINC) com um total de 108 esculturas, foi salvaguarda pelo acervo do Marco. Também em 2014, o Marco recebeu a exposição, Nos Caminhos Afro, fotografias em preto e branco do fotógrafo, etnólogo, antropólogo e pesquisador francês consagrado internacionalmente, Pierre Verger, cumprindo a terceira etapa de um projeto de itinerância da Petrobras.

Por meio do MARCO é possível traçar um panorama histórico e iconográfico das artes plásticas, fortalecendo a instituição como importante centro de fomento, debate e reflexão sobre a contemporaneidade.

Brandão (2007, p. 3) preconiza que: 
Ninguém escapa da educação. Em casa, na rua, na igreja ou na escola, de um modo ou de muitos, todos nós envolvemos pedaços da vida com ela: para aprender, para ensinar, para aprender-e-ensinar. Para saber, para fazer, para ser ou para conviver, todos os dias misturamos a vida com a educação. Com uma ou com várias Educações.

Dessa forma é importante entendermos que o papel do museu na formação da aprendizagem é de informação, de ação interdisciplinar, é primordial reconhecer que existem diferenças entre cada tipo de educação em função de seus espaços culturais e físicos, é essencial reconhecer a diversidade e amplitude de atuação da sociedade e do pedagogo, em especial, daqueles que atuam em um espaço museal ou em uma escola.

Os educadores e pedagogos do MARCO/MS atuam de modo interdisciplinar, planejando em equipe ações culturais, capazes de levar o aluno-visitante a se apropriar da obra exposta e da proposta do artista, inclusive oferecendo oficinas pedagógicas e momentos de contato direto com o artista, onde os alunos- escolas interpelam o autor acerca de suas obras, numa vertente sociocultural.

Situado no Parque das Nações Indígenas, em extensa área verde da cidade, local para atividades de lazer, o museu possui uma área construída de $4.000 \mathrm{~m}^{2}$, e dispõe de cinco salas de exposição, sendo uma com mostra de longa duração, de obras de seu acervo e quatro salas para as mostras temporárias que compõem sua programação anual.

O MARCO tem reservado um dia para limpeza e manutenção das instalações, sendo as segundas-feiras, em que está fechado à visitação, e para os demais dias da semana é estabelecido o seguinte horário de atendimento: terça a sexta feira, das 7 h30 às $17 \mathrm{~h} 30$ e aos sábados, domingos e feriados o horário é das $14 \mathrm{~h}$ às $18 \mathrm{~h}$, estando fechado para acesso ao público, apenas nos feriados de: $1^{\circ}$ de janeiro, sexta-feira santa, $1^{\circ}$ de maio (dia do trabalhador), finados (02 de novembro), Natal e 28 de outubro (dia do servidor público).

Vale destacar que além das exposições de arte o museu oferece uma extensa agenda cultural. Pois possui um auditório com capacidade para 105 pessoas e uma biblioteca específica em artes plásticas, com material para pesquisa e formação de estudantes, arte educadores, artistas e público em geral.

O MARCO, por meio de suas atividades, cumpre fundamental papel educativo, democratizando o acesso à arte e aos bens culturais, posicionando-se como importante centro de formação e fomento cultural. No ano de 2006, quando completou 15 anos, o MARCO/MS lançou seu website: www.marcovirtual.com.br, objetivando a difusão das artes plásticas sul-mato-grossenses e a aproximação com o público, local em que está disponível sua agenda de atividades gratuitas aos visitantes. 
Os museus são importantes centros de conhecimento, espaços de memória e cultura, pontos essenciais na construção dos saberes locais.

No que diz respeito à cultura e às novas tecnologias, surge a necessidade de reflexão acerca de como as instituições museológicas, espaços de reflexão acerca de como as instituições museológicas, espaços de memória e cultura, desde sua formação até a atualidade, vêm contribuindo para a difusão do conhecimento contido nesse espaço físico. Para atender às novas exigências e necessidades dessa sociedade da informação/conhecimento que se apresenta, é preciso pensar na lógica dessas informações de cunho histórico, político, científico, social e cultural (PADILHA; CAFÉ; SILVA, 2014, p. 71).

O grande desafio de um Museu de Arte Contemporânea é voltar-se para ações de formação de público, compondo estratégias junto aos visitantes principalmente às escolas para incentivar a frequência aos museus e oportunizar situações para futuros consumidores e apreciadores de arte moderna.

\section{O caráter pedagógico do museu/atividades educativas não- formais}

O setor educativo do MARCO/MS está em sintonia com as abordagens atuais da arte educação, composto por salas para as atividades práticas com escolas e grupos no complemento didático, por intermédio de agendamento com a equipe técnica do museu.

O programa educativo desenvolve ações educativas a partir das obras do acervo, promovendo a qualidade da experiência do público no contato com as obras, garantindo a ampla acessibilidade ao museu, incluindo ações destinadas às pessoas que habitualmente não são frequentadoras, e incentivando futuros apreciadores de arte contemporânea.

Busca atuar por meio de estímulos capazes de estabelecer diálogos com os visitantes, tendo como ponto de partida sua percepção, interpretação e compreensão das obras enfocadas, para a construção de significados possíveis. Tendo em sua equipe pedagogos, bibliotecários, arte-educadores e museólogos que em sintonia com as abordagens atuais da arte-educação, desenvolvem atividades práticas, com escolas e grupos no complemento didático, em visitas orientadas às exposições, além de cursos de iniciação em arte para crianças, jovens e adultos; assim como no equipado atelier para o desenvolvimento de técnicas de gravura. Sendo que, além das ações rotineiras de arte educação, há as oficinas sempre no período de férias escolares - julho e dezembro. O MARCO oferta diferentes oficinas regidas por artistas 
plásticos e arte-educadores, tais como as de Stop Motion, Desenho Mangá, Circo/expressão corporal e Arte em Miniaturas.

Composto por profissionais de diferentes áreas de atuação, que junto à equipe corroboram para o sucesso da atividade educativa não formal ofertada mensalmente pelo MARCO/MS.

No aporte de Chiavenato (2004, p. 5):

As organizações são constituídas de pessoas e dependem delas para atingir seus objetivos e cumprir suas missões. E para as pessoas, as organizações constituem um meio pelo qual elas podem alcançar vários objetivos pessoais, com um mínimo custo de tempo, de esforço e de conflito. Muitos desses objetivos pessoais jamais poderiam ser alcançadas apenas por meio do esforço pessoal isolado. As organizações surgem exatamente para aproveitar a sinergia dos esforços de vários indivíduos que trabalham em conjunto.

Após a visitação, quando previamente combinado, os grupos, ainda participam de oficinas que propiciam vivências plásticas. Essa prática compõe o projeto de oficinas permanentes, que visa estimular a criatividade artística dos participantes, promover o aprendizado dos fundamentos da linguagem visual e técnicas de arte, fomentar a formação de público em museus, incentivar a comunidade a interagir com seus espaços de arte e cultura.

O MARCO/MS oportuniza também frequentemente o curso de desenho cômico e linha-clara franco belga: voltado para crianças de 08 a 14 anos, favorecendo meios à aprendizagem de técnicas usadas pela maioria dos cartunistas norte-americanos nas suas "comics strips", as "tirinhas de jornal" e também as técnicas da linha-clara, usada pelos desenhistas do chamado mercado "franco-belga".

O MARCO/MS participa regularmente das ações e atividades planejadas pelo Instituto Brasileiro de Museus - IBRAM, tais como a semana de museus, ação de promoção permanente do Instituto, onde se congregam atividades diversas dos museus brasileiros, marcando o dia internacional de museus (18 de maio). E também a Primavera de Museus, programação anual do IBRAM, em que o MARCO recebe estudantes de escolas da rede pública e particular, previamente agendados, para participar da programação proposta pelo Instituto Brasileiro de Museus (IBRAM), a fim de estimular a capacidade de inovação de cada instituição.

O Projeto Conversando com o Artista, visa atender as escolas públicas ou privadas por meio da mediação com o próprio artista que participa das temporadas de exposições do MARCO. O projeto tem como objetivos familiarizar os estudantes com o museu, com a arte e 
principalmente o de aproximar o artista contemporâneo de seus ouvintes e o de conhecer o seu percurso criador, além de fomentar o público apreciador de arte.

A biblioteca do MARCO/MS oferta conhecimento, arte e cultura para todos, visando capacitar, estimular e ampliar o conhecimento do assunto - artes (com bibliografia especializada em arte moderna e contemporânea).

Seguindo uma agenda preparada pelo programa educativo, as escolas ao adentrarem ao museu são recebidas pelas mediadoras que, inicialmente, esclarecem sobre os procedimentos de visitação, acompanhando em seguida para as salas de exposições, estimulando o exercício de leitura das obras, não apenas dando respostas, mas também instigando perguntas, problematizando e mobilizando o potencial de cada um em torno da obra de arte.

\section{Considerações finais}

Fazendo uma analogia entre museu enquanto espaço material - edificado e museu espaço de memória. Aliando a reflexão acerca da arquitetura de museus para os dias atuais, veem-se os mesmos, enquanto espaços contenedores da arte contemporânea. E, assim como a arte é atemporal, os museus deveriam suportar todas as formas de manifestações artísticas. A arte contemporânea tem diversos significados, questionamentos, portanto vários autores apresentam definições que podem indicar o caminho para os projetos arquitetônicos dos museus contemporâneos.

Quanto às atividades educativas não formais, o setor educativo do MARCO/MS, está em sintonia com as abordagens atuais da arte educação, composto por salas para as atividades práticas com escolas e grupos no complemento didático, por intermédio de agendamento com a equipe técnica do museu. Consistindo em um programa bastante complexo de ações objetiva desenvolver ações educativas a partir das obras do acervo, promover a qualidade da experiência do público no contato com as obras, garantir a ampla acessibilidade ao museu, e incentivar futuros apreciadores de arte contemporânea.

\section{Referências}

BESSET, Maurice. Obras, espacios, miradas. El museo em lahistoriadel artecontemporâneo. Revista A \& V, n. 9, Madrid, 1993.

BOSI, Ecléa. Memória e sociedade: lembranças de velhos. São Paulo: Companhia das Letras, 1994, p. 90. 
BRANDÃO, Carlos Rodrigues. O que é educação. São Paulo: Brasiliense, 2007. (Coleção Primeiros Passos).

CASTILHO, Maria Augusta de; FERREIRA, Rejane Platero. O Museu das Culturas Dom Bosco: desenvolvimento local na educação básica. Campo Grande: Gráfica Nacional, 2012, p. 31-32.

CHIAVENATO, Idalberto. Gestão de pessoas. São Paulo: 2004.

DESVALLÉES, André; MAIRESSE, François. Conceitos-chave de museologia. Tradução e comentários de Bruno Brulon Soares e Marília Xavier Cury. São Paulo: Comitê Brasileiro do Conselho Internacional de Museus: Pinacoteca do Estado de São Paulo: Secretaria de Estado da Cultura, 2013, p. 64.

DURAND, Jean-Nicolas-Luis. Novo compêndio de lições de arquitetura. Tradução Igor Fracalossi. 20/02/2014. Disponível em: $<$ https://www.archdaily.com.br/br/01-169991/novo-compendio-de-licoes-de-arquitetura-slash -jean-nicolas-louis-durand>. Acesso em: 12 abr. 2016.

FONSECA, Elizabeth. Biografia - Antonio Nogueira da Fonseca. Série Campo Grande Personalidades. Campo Grande: Prefeitura Municipal de Campo Grande, 1997, p. 34.

HALBWACHS, Maurice. A memória coletiva. São Paulo: Vértice, 1990, p. 82.

HELLWIG, Alessandro Wickboldt. Museu, memória e identidade Pomerana: uma correlação local. Revista Expressa Extensão, v. 19, $\mathrm{n}^{\mathrm{o}}$ 2, 2014. Disponível em: $<$ https://periodicos.ufpel.edu.br/ojs2/index.php/expressaextensao/article/view/4481>. Acesso em: 9 abr. 2017.

IPHAN. Instituto do Patrimônio Histórico e Artístico Nacional. Caderno de diretrizes museológicas. 2. ed. Belo Horizonte: Secretaria de Estado da Cultura/Superintendência de Museus, 2006.

KESSEL, Zilda. Memória e memória coletiva na perspectiva. Disponível em: $<$ http://www.webartigos.com/articles/44296/1/memoria-e-memoria-coletiva-naperspectiva-zil da-kessel-/pagina1.html>.Acesso em: $12 \mathrm{dez} .2010$.

KIEFER, Flávio. Arquitetura de museus. ARQtextos, p. 12-25, 2000. Disponível em: <www.ufrgs.br/propar/publicacoes/ARQtextos/PDFs_revista_1/1_Kiefer.pdf $>$. Acesso em: 15 mar. 2016.

LE GOFF, Jacques. História e memória. São Paulo: Unicamp, 1996.

NORONHA, Elisa. Museus de Arte Contemporânea: uma estratégia de abordagem. Interartive. 2010, s/p. Disponível em: <http://interartive.org/2010/01/museucontemporaneo>. Acesso em: 9 abr. 2017.

PADILHA, Renata Cardoso, CAFÉ, Lígia, SILVA, Edna Lúcia da, O papel das instituições museológicas na sociedade da informação/conhecimento. Perspectivas em Ciência da Informação, v. 19, n. 2, p. 68-82, abr./jun., 2014.

RODRIGUES, Leo. Unesco reconhece a Pampulha como patrimônio mundial da humanidade. EBC Agência Brasil. 17/07/2016. Disponível em: 
$<$ http://agenciabrasil.ebc.com.br/cultura/noticia/2016-07/pampula-e-reconhecido-como-patri monio-mundial-da-humanidade>. Acesso em: 18 jul. 2016.

SANTOS, João Carlos Lopes dos. Arte contemporânea: afinal, o que é isso? Consultarte. Disponível em: <http://www.investarte.com/consultarte/scripts/acompanhando/67.asp>. Acesso em: 20 mar. 2016.

SEARING, Helen. New American Art Museums. Nova York: Whitney Museum of American Art, 1982.

SPERLING, David. As arquiteturas de museus contemporâneos como agentes no sistema da arte. Periódico Permanente, v. 1, n. 1, 2012. Disponível em: $<$ http://www.forumpermanente.org/revista/edicao-0/textos/as-arquiteturas-de-museus-contem poraneos-como-agentes-no-sistema-da-arte>. Acesso em: 8 abr. 2016, s/p.

THOMPSON, Paul. A voz do passado. Trad. Lólio Lourenço de Oliveira. Rio de Janeiro: Paz e Terra, 1992, p. 197.

TODOROV, Tzvetan. Memória do mal, tentação do bem - indagações sobre o século XX. São Paulo: Arx, 2002, p. 141.

VERUNCHK, Micheliny. Afinal, o que é arte contemporânea. Revista Continuum, mar./abril, 2009, Disponível em: $<$ http://old-portalic.icnetworks.org/materiacontinuum/marco-abril-2009-afinal-o-que-e-arte-co ntemporanea>. Acesso em: 20 abr. 2017.

VITRUVIO, Marco Lucio. Los diezlibros de arquitectura. Barcelona: Ibéria, 1955. Disponível em: <www.fau.usp.br/dephistoria/labtri/2.10livros.html>. Acesso em: 20 abr. 2016.

VON SIMSON, Olga Rodrigues. Os desafios contemporâneos da história oral. Campinas: UNICAMP, 2000. 